${ }^{6}$ Lyon, M F, and Hawkes, S G, Nature (London), 1970, 227, 1217.

Fredga, K, et al, Nature (London), 1976, 261, 225.

${ }^{8}$ Hamerton, J L, Human Cytogenetics, vol 2, p 169. New York, Academic Press, 1971

${ }^{9}$ Short, R V, Philosophical Transactions of the Royal Society of London. Series B. Biological Sciences, 1970, 259, 141.

1" McLaren, A, Mammalian Chimeras. London, Cambridge University Press, 1976.

11 Eichwald, E J, and Silmser, C R, Transplantation Bulletin, 1955, 2, 148.

12 Wachtel, S S, Immunological Reviews, 1977, 33, 3.

${ }_{13}$ Silvers, W K, and Wachtel, S S, Science, 1977, 195, 956.

${ }^{14}$ Boyse, E A, et al, Transplantation, 1970, 10, 446

${ }_{15}$ Shalev, A, Berczi, I, and Hamerton, J L, fournal of Immunogenetics, 1978, in press.

${ }^{16}$ Wachtel, S S, et al, Nezv England fournal of Medicine, 1976, 295, 750.

17 Dosik, S S, et al, fournal of the American Medical Association, 1978, 256, 2505.

1* Bennett, D, et al, Nature (London), 1976, 265, 255

19 Selden, J R, et al, Science, 1978, 201, 644.

21) Ghosh, S N, et al, Clinical Genetics, 1978, 14, 31 .

${ }^{21}$ Wachtel, S S, et al, Nature (London), 1976, 264, 638

22 Wachtel, S S, Science, 1977, 198, 797.

${ }^{23}$ Ohno, S, et al, Recent Progress in Hormone Research, vol 33, 1977. In press.

${ }^{24} \mathrm{Krco}, \mathrm{C}$, and Goldberg, E H, Science, 1976, 193, 1134.

$25 \mathrm{Koo}, \mathrm{G}$ C, et al, Science, 1977, 198, 940.

26 Ohno, S, et al, Nature (London), 1976, 261, 597.

27 Ohno, S, Human Genetics, 1976, 35, 21.

${ }^{28}$ Ohno, S, Nagai, Y, and Ciccarese, S, Cytogenetics and Cell Genetics, 1978, 20, 351 .

${ }^{29}$ Zenzes, M T, et al, Cytogenetics and Cell Genetics, 1978, 20, 365.

30 Ohno, S, et al, In Vitro, in press.

\section{Cure and survival in childhood cancer}

Survival for five years after the diagnosis and treatment of malignant disease in childhood is often thought of as synonymous with cure. This was probably the case with the early successes, when the survivors were mostly confined to patients whose disease was localised at diagnosis and completely removed surgically, or whose residual disease was eradicated by radiotherapy or short courses of chemotherapy. What is the outcome with longer follow-up?

Li $e t a^{1}$ have recently reported on the course of five-year survivors of childhood cancer in two large series, one from a group of co-operating institutions in the United States, and the other from patients treated at the Sidney Farber Cancer Institute. In the first study, 1807 patients from a total of 6153 diagnosed between 1950 and 1969 were alive five years later and in the second 425 out of 3631 (the lower proportion in the second series was due to excluding patients from analysis if they had not been referred to the institution within two months of diagnosis). In both groups roughly a further $10 \%$ died in the next five years, and the life table analyses showed projected survival of $83 \%$ and $79^{\circ}$ orespectively at 25 years-compared with an expected $97 \%$ in the general population. Clearly survival falls off after five years and continues to do so for a considerable time, and in these series the survival curve had not joined that of the general population at 25 years. Most of the deaths occurred in patients who had already suffered one relapse before entry to the study, and the chance of survival to 15 years in this group was only $54^{\circ} \circ$, compared with $92 \%$ in those who were in their first remission. One-third of the patients who subsequently died had leukaemia. Five deaths were due to second primary neoplasms, and seven to the effects of anti-cancer treatment.

Throughout the 1970s the trend has been to use more intensive chemotherapy programmes and to combine them with radiation. More effective treatment has led to many more children being free of disease five years after diagnosis. We cannot yet ascertain whether these children are really cured or whether the time of relapse has merely been delayed. The data of $\mathrm{Li}$ and colleagues suggest that the risk of late recurrence is maximal between five and nine years, and if intensification of treatment is simply delaying relapse it seems likely to occur at that stage. Beyond ten years from diagnosis the more important causes of morbidity and mortality are second primary neoplasms and the effects of treatment. ${ }^{2}{ }^{3}$ The size of the problem of second primary tumours, both benign and malignant, is still unknown. One specific association is that with osteogenic sarcoma, both within and remote from the radiation field, in survivors of retinoblastoma; tumours of other types may also be commoner in these patients and their relatives, suggesting a genetic predisposition to the development of malignancy. The second largest group of long-term survivors in the series described by $\mathrm{Li}$ et al was made up of children with nephroblastoma-the most common primary tumour in children who developed second tumours in Meadows's report. ${ }^{2}$

The frequency of second primary tumours in retinoblastoma and nephroblastoma may reflect the higher rates of survival in these groups, genetic predisposition, or the direct effects of treatment. Clearly data on long-term survivors must be based on treatments that are to some extent outdated. Nevertheless, the findings by $\mathrm{Li}$ et al show the need for careful follow-up of all long-term survivors of malignant disease in childhood.

${ }^{1} \mathrm{Li}, \mathrm{F} \mathrm{P}$, et al, fournal of Pediatrics, 1978, 93, 185

${ }^{2}$ Meadows, A T, et al, Cancer, 1977, 40, 1903.

3 Schwartz, A D, Lee, H, and Baum, E S, fournal of Pediatrics, 1975, 87, 374.

\section{Poisoning and enuresis}

"He still wets the bed, doctor." Too often this afterthought, produced as the mother is leaving the consulting room, induces a reflex stretching of the hand to the prescription pad for a tricyclic antidepressant. Use of the word enuresis has raised bed-wetting to the status of a disease that requires a drug to cure it-when in fact in most cases the child is normal.

About half of children are dry at night by the age of $2,75 \%$ by 3 , and $90 \%$ by 5 years. The annual spontaneous cure rate after five years is $14 \% .^{1}$ If the child is less than 5 years old excluding physical disease by examination of the urine for sugar, albumin, and infection and explaining the range of normality should be enough to satisfy the parents, and often is. Treatment is indicated only in older children, and the choice lies between incentive schemes using tokens such as coloured paper stars, a buzzer-and-pad waking device, or a tricyclic antidepressant. The waking device produces a long-term cure in $80 \%$ of children, ${ }^{2}$ but an antidepressant will suppress wetting completely in only about $30^{\circ},{ }_{0}^{3}$ and within three months of stopping treatment many will be wet again. ${ }^{3}$ This high relapse rate is acknowledged by one of the manufacturers of antidepressants, who provides free books of stars for use with its drugs.

Why are buzzers not used more frequently? Large numbers are available for loan in paediatric outpatient clinics, and many school clinics have a supply. District supplies officers can be persuaded to hold a stock, but doctors find it easier to write a prescription for an antidepressant than to persuade an administrator to buy, supply, and service the equipment. If antidepressants were completely safe their low success rate 